\title{
Effect of light, ultra violet and magnetized water on the growth and development of Dura (Sorghum sp.).
}

\author{
Elfadil, A. G. and R. A. Abdallah \\ Department of Biological Sciences \& Environmental Studies, Faculty of Science and \\ Technology, \\ AL-Née lain University, Khartoum, P .O. Box: 12702, Sudan. \\ Tel. +249912336119, E-mail: abualjack@hotmail.com
}

\section{ABSTRACT}

This study was conducted to determine the impact of sun light, UV and magnetized water on Dura Sorghum sp. variety plants the Sudanese main stable food. The morphological changes of the Sorghum plants in terms of plant height, color of leaves, growth and development was monitored. The impact of light stress on plants was done by isolating he plant from light for a period of time. The result showed that light stress resulted in retarding growth, yellowing of the leaves and finally plant death after a very short period time. Second the impact of UV on plants along different periods of time showed negatively effect. The effect of magnetized water on the plant indicated that magnetized water has a positive effect on Dura plant growth and development. Though light stress has a significantly negative impact on plant growth and could lead to its death.

Key words: Sorghum,Dura, UV, Magnetized water

\section{INTRODUCTION}

Plant development and productivity are negatively affected by environmental stresses. During the last decades, cultivated land in several regions of the world has been affected by environmental stresses like sun light, water deficit, salt, cold, drought and UV, which hinders crop cultivation and yield. Every year countries lose a substantial amount of money from reductions in crop productivity caused by abiotic stresses, (Goodman, L.A., 1960). It is predicted that these environmental stresses will become more intense and frequent with climate change, especially global warming. According to FAO, the world population is estimated to reach near 10 billion by 2050, which will witness serious food shortages, that needs $70 \%$ more food production, (Alan H. T., 1983). Therefore, tolerant crops these stresses should be developed to feed the increasing world population, (Goodman, L.A., 1960). Maintaining crop yields under adverse environmental stresses is probably the major challenge facing modern agriculture, where the plants might react to environmental stress on various levels: on the biochemical, cellular, or morphological scale, and at species or population level. The characteristics of organisms change with their size (allometric relationships), with their life history (and related allocation strategies) and with their functional evolution, (Alan, H. T., 1983). Morphogical response of plants to mechanical disturbance, depends on morphological characteristics, phenological stage, degree of stem sclerification and on trampling intensity, (Khan, N.A, \& Singh, S., 2008). Very few studies are dedicated of biological effects induced by sun light, UV (Bogenrieder, A., \& Klein, R. 1982) and magnetic water on living organism e.g. Dura plants in Sudan. In this study we investigated the sun light, UV and magnetic water influence on the Sorghum plant variety, which it is consider as the first crop in Sudan. It has been claimed that abiotic stress causes the most crop loss of any other factor and that most major crops were reduced in their yield by more than $50 \%$ from their potential yield (Tuteja, N., 2007). It has also been speculated that this yield reduction will only worsen with the dramatic climate changes expected in the future. Though abiotic stress is widely considered a detrimental effect, the research on this branch of the issue is extensive (Tuteja N, \& Sopory S.K., 2008). Plants have three basic responses or reactions to light, (photosynthesis, phototropism and photoperiodism). The most interesting response is photoperiodism, that the plant's reaction to dark and is controlled by the phytochrome pigment in the leaves. The pigment shifts between two forms based on whether it 
Agric. Biol. J. N. Am., 2013, 4(2): 91-96

receives more red or far red light. The reaction controls several different plant reactions including seed germination, stem elongation, dormancy, and blooming in day length sensitive plants (Urano, et al., 2004) the last photoperiod response is stimulation of dormancy. Several things trigger dormancy, but a major one is the shortening day length. This is critical when we move plants out of the area where they evolved (Zhang, et al., 2009). On these dark days remember your plants are reacting to the light or dark in multiple ways, (Barbara Larson, 2000 \& Ali, R.M. 2000). Water is paramagnetic - meaning that it will hold a magnetic charge. In nature, the earth's magnetic field naturally charges water in lakes, wells, and running streams. However, as water passes through treatment plants and is transported through pipes to your home or work place, it loses its magnetic charge. Treating water with magnetic fields simple restores the natural energy and balance that nature intended. Magnetized water has more hydroxyl $(\mathrm{OH}-)$ ions that form alkaline molecules which reduce the acidity (Huang, X.X., Bie Z.L., 2010). Normal tap water has a pH of about 7. Magnetized water is more alkaline and can have a $\mathrm{pH}$ as high as 9.2. Magnetizing water reduces the surface tension of the water it feel softer. It is thinner wetter, and more absorbable, so it is better able to penetrate cell walls and deliver the nutrients that it carries (Zhang W, et al., 2009). Although there is little research that proves the benefits of magnetized water, there aren't any signs that it harms your health or the health of your plants, (Lazzarato, L. et al., 2009). Since magnetized water is believed to dissolve more nutrients than regular water, the plants need less fertilizer. Plants treated with magnetized water are more robust than other plant which makes them better able to fend of pests and diseases. This decreases or eliminates the need for pesticides and fungicides, which are costly and often harmful to human and environmental health, (Shoeb, F., et al., 2001).

Objectives: $1 \backslash$ Objectives: $1 \backslash$ to detect the magnitude of morphological changes (leaf area, plant height and color) and induced by light, UV stress and magnetic water on Sorghum sp.; $2 \backslash$ to determine the influence of abiotic stress on growth development and production Sorghum sp. (Dura variety); and $3 \backslash$ to recommend improve methods to sustain the productivity .

\section{MATERIALS AND METHODS}

The study targeted the environmental stress on plant and its effects upon the Dura plant growth, development and productivity. The three experiments are: a) effect of Light stress; b) effect UV; and c) effect of magnetized water on plant. Sorghum Sp. (Dura Tabut variety) was used for this study. It was sown inside plastic bags, each bag have 500 g. of Silt soil. In each bag four seeds were sown, only three healthy seedlings were maintained in each bag. In each experiment there were 3 replicates and there were control inside the green house and one more control outside the green house (as natural field conditions). The healthy seedlings were watered with equal amount of tape water daily at noon and maintained for two weeks. During this time the plants growth and development were daily noted. Observations of length of plant was taken; every 3 days and the wet and dry weight at the end of each experiment. Experiment of light stress: A special wooden box (1*2 feet) was used to isolate the plants from sun light. Three replicates, each bag has three healthy seedlings of plants. After one week age plant exposed to light stress for seven days. Experiment of magnetized water: Three plants were watered with magnetized water daily for 2 weeks. Magnetized water was prepared by passing piped water through a bio-disc. The Bio Disc is a natural energy generating device that produces scalar energy frequencies that have no negative side effects. The energy created specifically rejuvenates molecular structures in all liquids. The molecular structure causes any liquid to become more hydratious, taste better and extend shelf life. The Bio Disc is made of 13 technically engineered natural minerals (Limpert, GJC \& Raber, JL, (1985).. Soil used in the study was obtained from the Nile River area. The soil sample was analyzed at the National Center for Desertification Research Institute, by atomic absorption spectrophotometer, Model 210 VGP., made in U.S.A. The analysis of $\mathrm{Na}, \mathrm{k}$ and $\mathrm{P}$ was done by Atomic absorption spectrophotometer. Data was analyzed using origin programme. In addition to that statistical analysis using variance (Goodman, LA., (1960) and ANOVA test was done.

\section{RESULTS}

This study was conducted to investigate the effect of a biotic stress on plant such as light and magnetized water. Light stress effect on plant growth and morphology more than the other factors. The results 
that has obtained from this study that light effects negatively on plant and the magnetized water acts positive with plant and we found that it improves plant growth and production. The results of this study were compared with the control plant inside the green house to see the variation in growth and morphological changes and also the biomass of

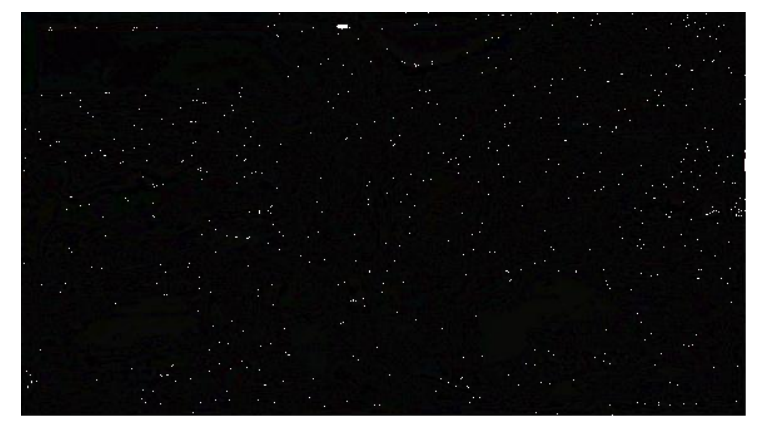

Plate 1: Control in side green house

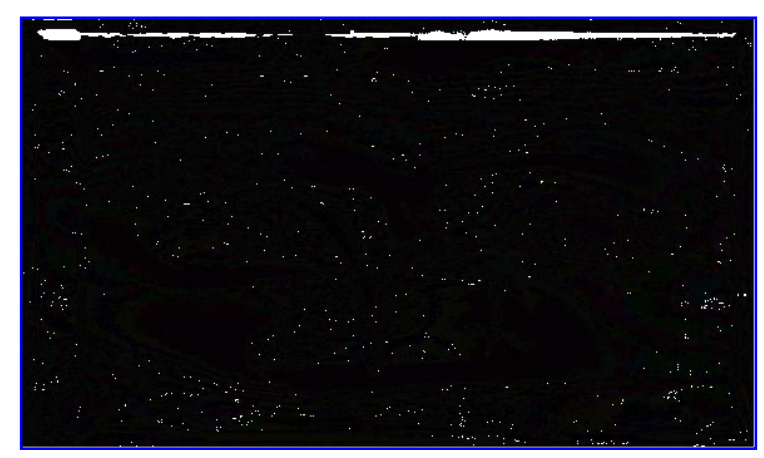

Plate 3: Sun light plants was compared with the control (inside the green house) biomass. The control plant outside the green house was affected by environmental conditions such as winds and high temperature and the growth was weak comparing with the control inside the green house

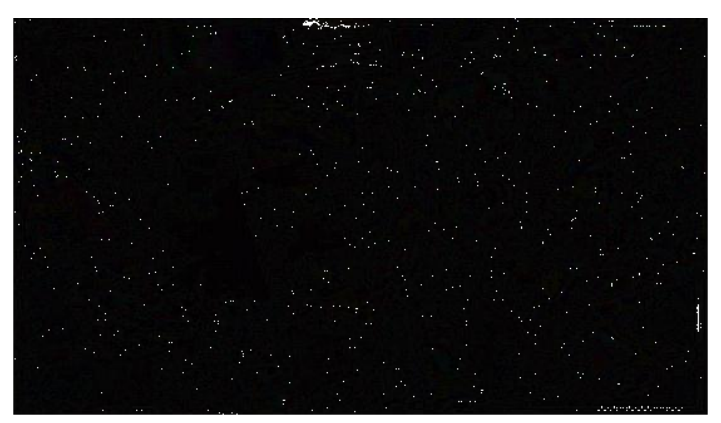

Plate 2: Ultraviolet

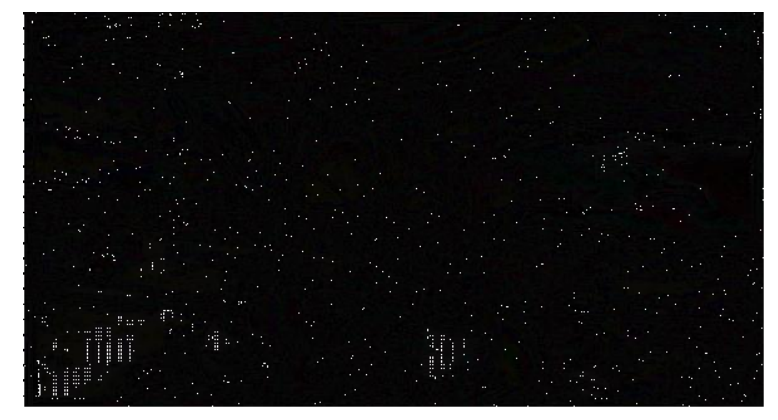

Plate 4: Magnetized water 


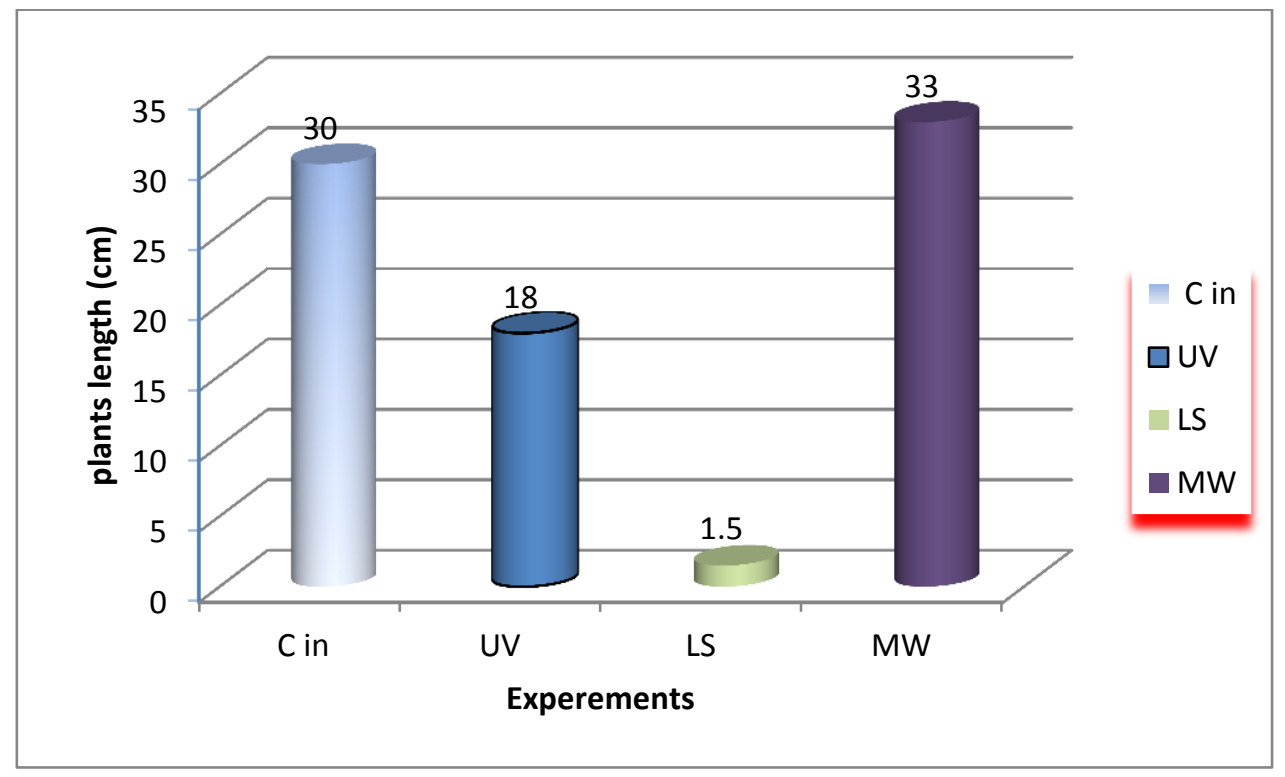

Fig.1: Describes and shows the variation on growth of plant in each experiment in centimeters Where: $\mathrm{C}$ in=control inside the green house, $\mathrm{UV}=$ ultra violet, $\mathrm{SL}=$ sun light $\& \mathrm{MW}=$ magnetized water.

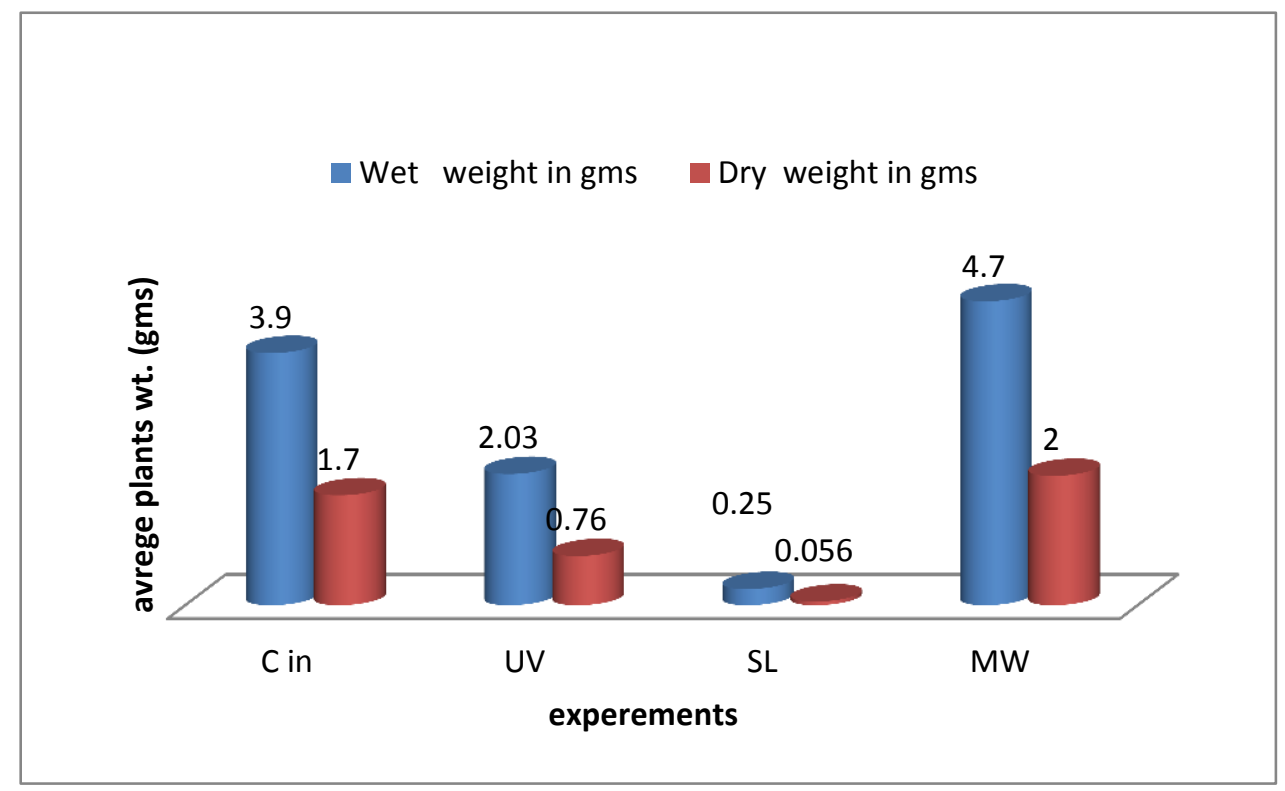

Fig.2: Showing the wet and dry weight of plants in grams

Where: $\mathrm{C}$ in=control inside the green house, $\mathrm{UV}=$ ultra violet, $\mathrm{SL}=$ sun light $\& \mathrm{MW}=$ magnetized water. 


\section{DISCUSSION}

This study was carried out to recognize the effect of abiotic stress on Sorghum plant, as environmental stress became a major problem that hinders crop cultivation and yield in the last years. Every year countries lose a substantial amount of money from reductions in crop productivity caused by a biotic stresses by Goodman, L.A., (1960). This study showed that environmental stress (abiotic), affect organisms in a variety of ways, these effects may be either beneficial or detrimental agreeing with finding of Tuteja N., (2007), and the deterioration in the quality of the environment (abiotic), biotic stressors are the major cause of the decline in plant species, and our findings agree with the works of Khan N.A., \& Singh S., (2008) and Bogenrieder, A., and Klein, R. (1982). We used the length of plant and the total biomass shown in fig. 1 \& 2 , to compare between the different stressors to see which more affect on the plant growth shown in fig. 1 and there had been sightings to identify morphological changes of the plant as a result of these factors similar to the results of Jordan et. al, (1989) Also the biomass of all the plants was compared with the control inside the green house as in fig. 2. Statistical analysis was done to see the significance and the mean, median and standard deviation for the plants of the experiments for each day was obtained, the results were close and this indicates the validity of tests or experiments. The major findings of this study are that, light stress affects the plant at a very high level more than other factors. The experiment of light stress even did not take much time; after two days of isolating the plant from sun light; the plant growth stopped, the leaves color changed into yellow, plate 3 , and the Plant died after only one week of the experiment. Barbara Larson, in 2000 stated that the plant has three basic responses or reactions to light. They are photosynthesis, phototropism and photoperiodism, and the light is the key factor for the growth of plants and the process of photosynthesis. The result showed that the absence of light affects negatively on the growth of plants and the germination of seeds and the length of stem and leaves and here our finding in confirmative with the results of (Barbara Larson, (2000). UV irradiation has no effect on photosynthetic characteristics of Dura plant in a agreement with Beyschlag, et. al.,(1988). In fact there was decrease of plant height, fresh mass of leaves, shoots and roots and poor plant growth comparing with the control as in plate 2 and this correspond with results of Zhang W.et.al., (2009). The experiment of magnetized water showed positive results on the growth of plants (plate 3), growth was excellent compared with the control inside the green house (plate 1). Though there is little research that proves the benefits of magnetized water, but there aren't any signs that it harms health of plants by Jordan, et al., (1989) and this is in agreement with our result as it has been shown in fig.1. The plant appearance of phenotype looks healthier as shown in plate 4. This study identified the effect of different stressors on plant and highlighted the importance of knowledge about environmental stress to address these problems and protect agricultural production and plants. In addition, it explained the positive impact of magnetized water, which can be used in the irrigation to improve soil fertility, the plant growth, increase the quality, and productivity of the Dura and plants in general. Our statistical analysis showed that there is significance and showed the validity of the experiments.

\section{CONCLUSIONS}

Based on the findings of this study we conclude that, environmental stress (abiotic) causes reduction, loss in crops and vegetation and it is a series problem that must be taken into account. Our study also showed the response of plant to different stressors (light, magnetized water and UV) resulted on plant growth and the morphological changes. Despite the negative impact of the effects of the light, but the effect of magnetized water on the plant had a positive effect and this result was amazing as it was said that the water of life. This finding showed that a biotic stress can be used to improve plants and crops quality and productivity by different ways according to types of stressor and there magnitude. Through this study, we have noted that there is a lack of information and studies related to this phenomenon, particularly in Sudan, but all the attention to the environmental stress is well documented in developed nations. Statistical analysis showed the significance and the validity of the experiments in which the mean, median and standard deviation were close at the three replications $\mathrm{R} 1, \mathrm{R} 2, \mathrm{R} 3$ (three plants in each experiment) of the study .

\section{RECOMMENDATION}

1. The knowledge about environmental stress in Sudan needs to be addressed, as it is major problem affects agricultural production and plants in general.

2. Importance of using magnetized water in irrigation to increase Sorghum sp. and crops species quality and productivity. 


\section{REFERENCES}

Alan H. Teramura (1983). Effects of ultraviolet-B radiation on the growth and yield of crop plants. Physiologia Plantarum58: 415-427.

Ali RM. (2000). Role of putrescine in salt tolerance of Atropa belladonna plant. Plant Science 152:173-179.

Barbara Larson, (2000).winter gardening tips. plants and light. http.//urbanext.illinois.edu/hortihinls/00112b.

Beyschlag W., P. W. Barnes, S. D. Flint, and M. M. Caldwell (1988). Enhanced UV-B irradiation has no effect on photosynthetic characteristics of wheat (TriticumaestivumL.) and wild Oat (AvenafatuaL.) under greenhouse and field conditions. Photosynthetica 22: 516-525.

Bogenrieder, A., and R. K (1982). Does solar UV influence the competitive relationship in higher plants? In J. Calkins [ed.], the role of solar ultraviolet in marine ecosystems.641-649. Plenum Press, New York and London.

Goodman, L.A (1960). On the exact variance of products. American Statistical Association Journal 55: 708-713.

Huang XX, Bie ZL(2010). Cinnamic acid-inhibited ribulose1,5 -bisphosphate carboxylase activity is mediated through decreased Spermine and changes in the ratio of polyamines in cowpea. J Plant Physiol 167:47-53.

Jordan P.W, Barnes, Gold W.g, Flint S.D. and Caldwell M.M, (1989). Competion, morphology and canopy structure in wheat (Triticumaestivum L.) and wild oat (Avenafatua L.) exposed to enhanced ultraviolet Bradiation.2,319-330.
Khan NA, Singh S (2008). A biotic Stress and Plant Responses. IK International, New Delhi.

Lazzarato L, Trebbi G, Pagnucco C, Franchin C, Torrigiani $P$, Betti $L$ (2009). Exogenous spermidine, arsenic and baminobutyric acid modulate tobacco resistance to tobacco mosaic virus, and affect local and systemic glucosylsalicylic acid levels and arginine decarboxylase gene expression in tobacco leaves. J Plant Physiol. 166:90-100.

Shoeb F, Yadav JS, Bajaj S, Rajam MV (2001). Polyamines as biomarkers for plant regeneration capacity: improvement of regeneration by modulation of polyamine metabolism in different genotypes of Indian rice. Plant Sci. 160:1229-1235.

Tuteja N (2007). Mechanisms of high salinity tolerance in plants. Meth Enzymol: Osmosens Osmosignal; 428:419-438.

Tuteja N, Sopory SK (2008). Chemical signaling under a biotic stress environment in plants.Plant Signal Beh.2008; 3:525-536.

Urano K, Yoshiba Y, Nanjo T, Yamaguchi-Shinozaki K, Shinozaki K (2004). Arabidopsis stress-inducible gene for arginine decarboxylase AtADC2 is required for accumulation of putrescine in salt tolerance. Biochem.Biophys. Res. Commun. 313:369-375.

Zhang W, Jiang B, Li W, Song H, Yu Y, Chen J ( 2009). Polyamines enhance chilling tolerance of cucumber (Cucumissativus L.) through modulating antioxidative system. ScientiaHorticult 122:200-208. 